\title{
CHARACTERIZATION OF ABNORMALITIES IN THE VISUAL SYSTEM OF THE MUTANT MOUSE PEARL ${ }^{1}$
}

\author{
GRANT W. BALKEMA, JR., ${ }^{2}$ LAWRENCE H. PINTO, URSULA C. DRÄGER, ${ }^{3}$ AND \\ JOSEPH W. VANABLE, JR.
}

Department of Biological Sciences, Purdue University, West Lafayette, Indiana 47907

\begin{abstract}
Mice of the mutant strain pearl (pe/pe) differ from the wild strain by a single gene mutation, which leads to a lightening of the coat color. We tested this strain to see if this mutant gene also expressed itself in one or more visual abnormalities. Pearl mice were found to lack totally the optokinetic nystagmus reflex that was present in every normal mouse that we examined. This lack of optokinetic nystagmus was not due to oculomotor defects, since postrotatory nystagmus was normal. As described for other pigmentation mutants, we found that pearl mutants had a reduced ipsilateral projection to the lateral geniculate nucleus, superior colliculus, and visual cortex. We recorded from single cells in the superior colliculus and found response properties and light sensitivities to be normal over the luminance range at which optokinetic nystagmus was tested. However, at very dim backgrounds (scotopic levels), the incremental sensitivities of these cells in pearl mice were about 100 times lower than those of normal mice. This reduction in sensitivity was restricted to scotopic backgrounds and was not due to abnormalities in either the time course of dark adaptation or the receptive field sizes of single cells. In recordings of the electroretinographic response, both the waveforms and the normalized magnitudes of the $A$ and $B$ waves of pearl were indistinguishable from those of normal mice, which seems to indicate that the cause of pearl's sensitivity defect is located central to the main electrical events in the photoreceptors. The normality of many aspects of the visual system of pearl mice contrasts sharply with the complete absence of optokinetic nystagmus, with the reduced ipsilateral projection, and with the reduced dark sensitivity of the cells in the superior colliculus.
\end{abstract}

Among the millions of mice bred each year for research occur many spontaneous mutations. Some mutations, such as those that cause changes in coat color, are readily detected and isolated. When these mutations are maintained on the inbred strain in which they arose, the resulting congenic strains differ from the parent strain by a mutation at only a single locus. The gene alterations that are expressed in easily observable symptoms, such as pigmentation abnormalities, also might cause specific changes to the visual system.

Mutants showing specific alterations within their visual systems are useful for a variety of reasons. First, the various phenotypical expressions of a single gene mutation indicate some commonality of mechanism at each one of these phenotypical expressions. For example, there

\footnotetext{
${ }^{1}$ This work was supported by numerous grants from the National Eye Institute, which we gratefully acknowledge. We thank R. W. Rodieck, A. Bunt, and J. Dineen for reading the manuscript.

${ }^{2}$ Present address and that to which correspondence should be addressed: Department of Ophthalmology RJ-10, University of Washington, School of Medicine, Seattle, WA 98195.

${ }^{3}$ Present address: Department of Neurobiology, Harvard Medical School, Boston, MA 02115.
}

must be a common mechanism, at some level, between the pigmentation of a mouse and the development of the ipsilateral projection of its retinal fibers. 'To understand aspects of the development of pigmentation thus may help in the understanding of the development of the visual pathway. Secondly, the alterations in the phenotype caused directly by the mutation may cause other indirect alterations of the visual system, and a study of these secondary alterations can reveal aspects of the general developmental process. Examples may be the ways in which the retinal fibers of a hypopigmentation mutant redistribute themselves in the lateral geniculate nucleus (Guillery, 1969) and the ways in which the geniculate fibers of the Siamese cat attempt to distribute themselves in a retinotopic manner on reaching the striate cortex (Hubel and Wiesel, 1971). Thirdly, the phenotypic expressions of a mutant gene may provide an animal model for human diseases; an example is the RCS rat as a model for retinitis pigmentosa (Dowling and Sidman, 1962).

One visual response that is readily evaluated is optokinetic nystagmus. Possible disturbances of visual function which will alter this reflex range from transparency of the ocular media to oculomotor abnormalities. Mitch- 
iner et al. (1976) have developed a method to observe optokinetic nystagmus in mice. Of the many mutant strains of mice that are maintained at the Jackson Laboratory in Bar Harbor, ME, we tested over 50 strains congenic to the $\mathrm{C} 57 \mathrm{BL} / 6 \mathrm{~J}$ inbred strain and found several that lack optokinetic nystagmus. Investigations on the visual system of one of these mutants, the pearl mouse, are the subject of this report.

The pearl mutation (Sarvella, 1954) is recessive and has heen mapped to chromosome 13 (Green, 1966). There are two lines of evidence to support the view that the pearl mutation is a point mutation. First, there is a high rate of somatic reversions to the wild phenotype (Russell and Major, 1956). Secondly, a mutation that occurs at the same locus as pearl has arisen spontaneously a second time (A. E. Searle, personal communication), and the phenotype of this strain appears to be identical to the pearl strain. The pearl mutation is kept on the C57BL/ 6J strain, where it leads to a light brownish grey coat in homozygous pearl mice compared to the black coat of the parent inbred strain. No abnormalities other than coat color have been associated previously with the pearl locus.

We report here that this hypopigmentation mutant lacks optokinetic nystagmus, shows a decreased ipsilateral component in its retinal projection, and has a decreased light sensitivity in the dark-adapted state. Other features of pearl's visual system, however, were normal; for example, the light-adapted sensitivity was indistinguishable from that of the wild type. The lack of optokinetic nystagmus in pearl thus is not due to a general deterioration of the visual system. Rather, this mutation causes at least three independent and specific alterations to the visual system.

\section{Materials and Methods}

\section{Experimental animals}

The mice were of the $\mathrm{C} 57 \mathrm{BL} / 6 \mathrm{~J}$ inbred strain; normal mice $(\mathrm{C} 57 \mathrm{BL} / 6 \mathrm{~J}+/+)$ were compared with the congenic strain pearl (C57BL/6J pe/pe), which were offspring from a pe/ + female and a pe/pe male breeding pair. Mice were kept in a standard laboratory environment under a 12-hr/12-hr light/dark cycle. The luminance in the cages averaged 0.8 to $10 \mathrm{~cd} / \mathrm{m}^{2}$. Mice used in these studies weighed between 19 and $26 \mathrm{gm}$; ages were between 8 weeks and 6 months.

\section{Morphological studies}

For structural studies of the retina, mice were anesthetized with ether and perfused with half-strength Karnovsky's fixative. The corneas were slit and the heads stored for $24 \mathrm{hr}$ in the same fixative. The eyes were removed, bisected along the vertical meridian, embedded in Epon/ Araldite, sectioned $1 \mu \mathrm{m}$ thick, and stained with toluidine blue (see LaVail and Battelle (1975) for details).

For studies of cytoarchitecture, mice were anesthetized with pentobarbital and perfused with $10 \%$ buffered formalin. The brains were removed, placed in Bouin's fixative for $24 \mathrm{hr}$, blocked, and stored in $10 \%$ buffered formalin for 2 weeks before they were embedded in paraffin, sectioned, and stained with cresyl violet.
For studies of retinal projections, a mixture of $\left[{ }^{3} \mathrm{H}\right]-$ fucose and $\left[{ }^{3} \mathrm{H}\right]$ proline $(14 \mathrm{Ci} / \mathrm{mmol}$ and $7 \mathrm{Ci} / \mathrm{mmol} ; 100$ $\mu \mathrm{Ci}$, total dose; New England Nuclear) was injected intravitreally into one eye of normal and pearl mice. After 10 days, the mice were anesthetized and perfused with formalin. The brains were sectioned on a freezing microtome, mounted on slides, coated with photographic emulsion (Kodak NTB2), exposed in the dark for 3 to 8 weeks at $4^{\circ} \mathrm{C}$, and developed with Dektol.

\section{Electrophysiological studies}

For all of the physiological experiments, the mice were dark-adapted for $12 \mathrm{hr}$. Just prior to the surgery, they were given a single dose of pentobarbital $(60 \mathrm{mg} / \mathrm{kg}$, i.p.) and chlorprothixene (Taractan, $0.13 \mathrm{mg}$, i.m.) to induce anesthesia and atropine sulfate $(0.1 \mathrm{mg}, \mathrm{s.c}$.$) to reduce$ mucus secretions.

Electroretinogram recordings. An $8 \times 8 \mathrm{~cm}$ transilluminated diffusing surface (obeying Lambert's cosine law) was positioned a few millimeters from the cornea so that it occupied nearly all of the visual field of one eye. The stimulus was a $125-\mathrm{msec}$ white light flash. Electroretinograms (ERG) were recorded between wick electrodes on the cornea and the back of the animal's head. Averaged responses to 10 stimulus presentations were obtained for the three dimmest stimuli $\left(1.67 \times 10^{-3}, 6.6 \times\right.$ $10^{-3}$, and $\left.1.32 \times 10^{-2} \mathrm{~cd} / \mathrm{m}^{2}\right)$; for brighter stimuli $(2.63 \times$ $10^{-2}$ to $1 \times 10^{4} \mathrm{~cd} / \mathrm{m}^{2}$ ), only one stimulus presentation was used at each stimulus luminance. To minimize light adaptation by the test stimulus, we allowed $2 \mathrm{~min}$ to elapse between each stimulus presentation. To ensure that the stimuli did not adapt the B wave, we presented a very dim test light before and after each stimulus. Using this protocol, four bright $\left(5.25 \times 10^{2} \mathrm{~cd} / \mathrm{m}^{2}\right)$ stimuli were presented-each of which was bright enough to adapt the $B$ wave-and we found that the amplitude of the $\mathrm{B}$ wave was reduced by $16 \%$. Therefore, during actual testing conditions, one could expect the $525 \mathrm{~cd} / \mathrm{m}^{2}$ stimulus to adapt the following response by roughly $4 \%$, in addition to the response that it produced.

Superior colliculus recording. No additional pentobarbital was given after surgery; anesthesia was maintained with a nitrous oxide/oxygen mixture during the recording session. To prevent atelectasis, we briefly inflated the mouse's lungs every $20 \mathrm{~min}$ to a volume 10 to $20 \%$ greater than end inspiratory volume. Arterial blood chemistry from animals prepared in this manner was found to be within the normal range for mammals. Small doses of atropine $(0.04 \mathrm{mg})$ were given every $3 \mathrm{hr}$ since, in some rodents, atropine is broken down rapidly (Sawin and Glick, 1943). By administering atropine in this way, the heart rate was kept within the normal range (Dawe, 1953). Prednisolone acetate (2 $\mathrm{mg}, \mathrm{i} . \mathrm{m}$.) was used to reduce cerebral edema.

The mouse was mounted in a stereotaxic instrument as described by Montemurro and Dukelow (1972) and Dräger (1975); a local anesthetic, procaine, was applied to all pressure points. A small area of the skull above the superior colliculus was removed; a petroleum jelly ring was built up around the hole in the skull and filled with saline. The body temperature of the mouse was maintained at $36.6 \pm 0.2^{\circ} \mathrm{C}$. 
After induction of anesthesia, the eyes were covered with black opaque tape. Following surgery, the eye covers were removed under dim light and $4 \%$ atropine sulfate was applied topically to maintain maximal mydriasis. The cornea and conjunctiva were anesthetized with $0.25 \%$ tetracaine $\mathrm{HCl}$ (Pontocaine, Winthrop) and plastic contact lenses $(1.5-\mathrm{mm}$ radius of curvature) were inserted. To ensure a constant pupillary diameter from animal to animal, each contact lens was opaque except for a 0.9 -mm-diameter artificial pupil.

Stimulators. Four incandescenl projection systems were used. (1) A constant background was provided by a $40-\mathrm{W}$ bulb illuminating the tangent screen with a 0.4 $\mathrm{cd} / \mathrm{m}^{2}$ uniform luminance. (2) A spot stimulator with a luminance of 5 to $100 \mathrm{~cd} / \mathrm{m}^{2}$ was used to locate the receptive fields of single units. (3) An adjustable test background was provided by a modified slide projector with a l-kW tungsten source and neutral density filters that allowed the luminance to be varied from $10^{-4}$ to 300 $\mathrm{cd} / \mathrm{m}^{2}$. (4) The adjustable rest spot stimulator consisted of a 500-W quartz halogen source, neutral density filters, and adjustable rectangular and circular masks and produced a luminance between $5 \times 10^{-4}$ and $300 \mathrm{~cd} / \mathrm{m}^{2}$.

Light measurements and calculations. We measured the luminance of a stimulus spot on the tangent screen with two separate photometers (United Detector Technology and Gamma Scientific, Inc.) and calculated the effective scotopic flux upon the retina using the following equation, compiled from Hardy and Perrin (1932), Rodieck (1973), and Wyszecki and Stiles (1967):

$F_{e}\left(\frac{\text { photons }}{\operatorname{rod} \cdot \sec }\right)$

$$
=B \pi\left(\frac{N_{o}}{N_{a}}\right)^{2}\left(\sin ^{2} \theta\right)(A)\left(\eta\left(1-10^{-\epsilon \rho}\right)\right)\left(\frac{1}{K_{m}^{\prime}}\right)\left(\frac{\text { photon }_{500}}{h c / \lambda}\right),
$$

where $B$ is the luminance of the tangent spot; $N_{o}$ and $N_{a}$ are the indices of refraction of the ocular media and air; $\theta$ is the angle subtended by a radius of the pupil as seen from the retina $=23^{\circ} ; A$ is the retinal area of the stimulus; $\eta$ is the quantum efficiency of rhodopsin $=0.62$ (Dartnall, 1972); $\epsilon$ is the specific absorbance of rhodopsin $=0.014 / \mu \mathrm{m}$ (Liebman and Entine, 1968); $\rho$ is the length of a mouse rod $=25 \mu \mathrm{m}$ (Carter-Dawson and LaVail, $1979) ; K_{m}{ }^{\prime}$ is the primary standard of light $=1945$ lumens/W; and $h c / \lambda$ is the energy of a photon at $500 \mathrm{~nm}$. Thus, a stimulus of luminance $1 \mathrm{~cd} / \mathrm{m}^{2}$ will result in a photon catch of about 1000 photons/(rod $\cdot \mathrm{sec})$.

Recordings. Using the constant background stimulator and the hand-held spot stimulator, units were isolated, mapped, and characterized in the superficial layers of the superior colliculus. The mouse then was dark-adapted for at least $5 \mathrm{~min}$. Stimuli of luminance sufficient to evoke 1 to 2 extra spikes were flashed on the cell's receptive field by the adjustable test spot stimulator. The test spot luminance was increased in several 0.2 - to 0.3 log-unit steps at each background and then this procedure was repeated at backgrounds that were increased in luminance successively by 0.6 -log-unit steps.

We were concerned with the possibility that the procedure for measuring the sensitivity did, in itself, lower the sensitivity of the cell being tested. To check for this, we first tested incremental sensitivity at three backgrounds $\left(10^{-4}, 1\right.$, and $\left.200 \mathrm{~cd} / \mathrm{m}^{2}\right)$. After dark-adapting the retina for $20 \mathrm{~min}$, we once again generated an incremental sensitivity curve but now testing at 10 backgrounds ranging from $10^{-4}$ to $200 \mathrm{~cd} / \mathrm{m}^{2}$. We found the latter method decreased the light sensitivity at the brightest backgrounds by less than 0.1 log unit.

In addition to the 5-min dark adaptation periods before the measurement of the dark-adapted sensitivity, we also examined the time course of dark adaptation from single cells in both pearl and normal mice. In these cells, we first determined the incremental sensitivity curve at three or four different backgrounds. We then flooded the tangent screen with a diffuse, bright $\left(600 \mathrm{~cd} / \mathrm{m}^{2}\right)$ adapting light for $3 \mathrm{~min}$. After the adapting light was switched off, we determined the interpolated stimulus luminance for 3.5 extra spikes, at 2-min intervals, until the cell recovered its original sensitivity.

Data analysis. Action potentials were recorded from single cells with glass-insulated tungsten electrodes (Levick, 1972) and were converted into 1-msec standard pulses. The response of each cell was accumulated in a pulse density record (10-msec time constant). The interpolated stimulus luminance for a cell was calculated by interpolating the luminance of the stimulus spot that would have been required to generate 3.5 extra spikes at each background luminance. The curve formed by plotting the interpolated stimulus luminance against the background luminance was defined as an incremental sensitivity curve (see Fig. 6).

\section{Results}

\section{Behavior}

Mutant mice were screened for the presence of horizontal optokinetic nystagmus (OKN) using Mitchiner et al.'s (1976) screening device. Rotation of a vertically striped drum elicited optokinetic nystagmus in every normal $(+/+)$ mouse tested (Fig. $1 A)$. Under the given test conditions, each rotational phase resulted in an average of 2.4 smooth pursuit movements, each of which was followed by a saccade. Mice with hereditary retinal degeneration (C57BL/6J le/rd le/rd, 4 to 6 months old) served as negative controls; they never showed optokinetic nystagmus under the test conditions (Fig. 1A). They are, however, not completely blind, as has been reported previously (Nagy and Misanin, 1970; Dräger and Hubel, 1978) and also is demonstrated below.

We have now screened over 50 different mutant stocks for optokinetic nystagmus. Seven mutants lacked this reflex and were among the 12 coat color mutants that were tested. One of these mutants, pearl, was selected for a more thorough examination (Fig. $1 A$ ).

To test if pearl mice were able to produce OKN at different luminances or angular velocities than used in Mitchiner's protocol (1976), we varied the luminance of the dim stripes from 0.1 to $10 \mathrm{~cd} / \mathrm{m}^{2}$ and varied the drum speed from 3 to $30^{\circ} / \mathrm{sec}$. Although normal mice consistently showed optokinetic nystagmus under all conditions, pearl mice never did.

To test if pearl mice were blind, we compared the pupillary light reflex of pearl mice with that of normal mice and with that of retinal degenerate mice. Mice with retinal degeneration showed little reduction in pupil size from dark-adapted values unless presented with very 
A

OKN NUMBER AND DIRECTION
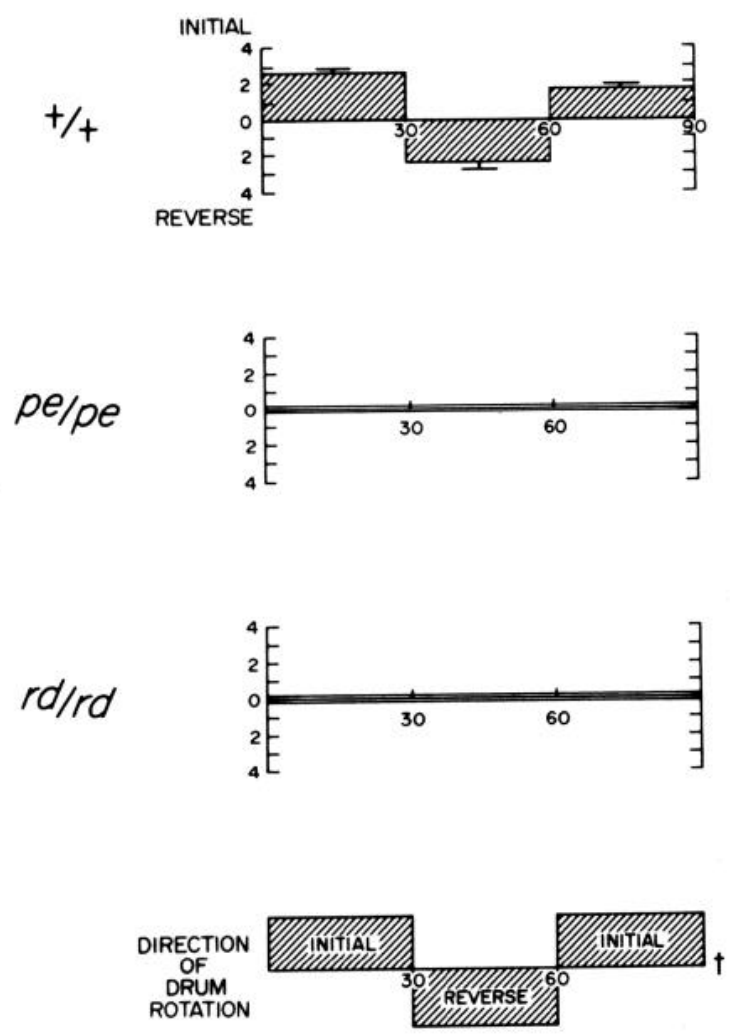

B
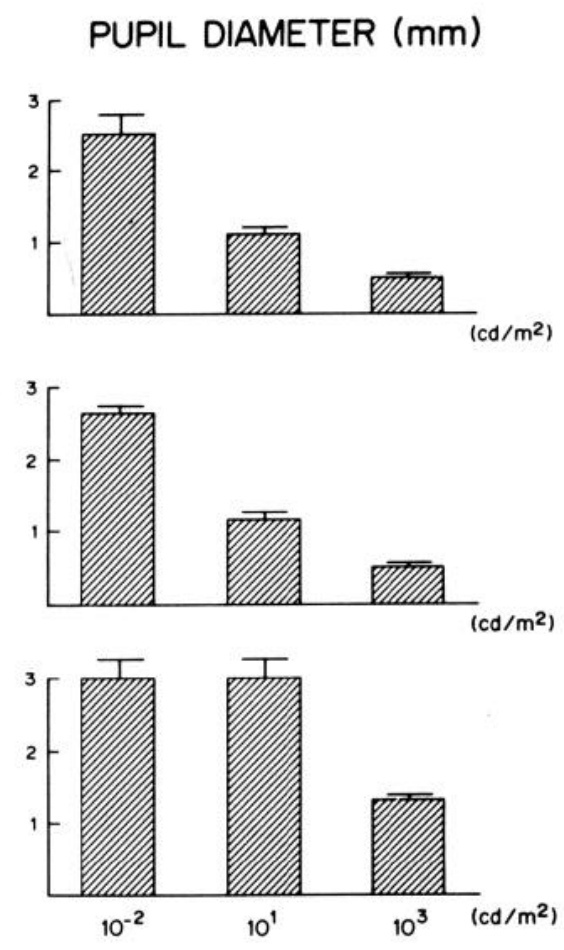

NUMBER OF PRN'S/SEC
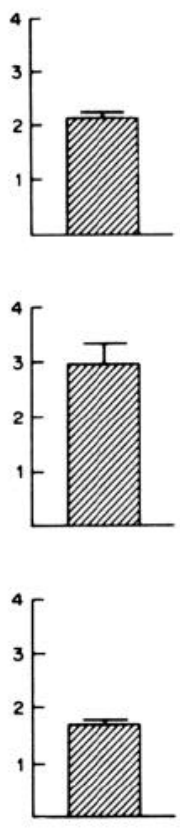

Figure 1. Behavioral results. A, Optokinetic nystagmus: the mean number of optokinetic eye movements is plotted against time for normal mice $(+/+)(n=50)$, pearl mice $(p e / p e)(n=23)$, and retinal degeneration mice $(r d / r d)(n=10)$. The direction of drum rotation is indicated at the bottom. The horizontal bars indicate the standard error of the mean. $B$, Pupillary light reflex: the diameter of the pupil (in millimeters) is indicated for normal $(n=10)$, pearl $(n=23)$, and retinal degeneration mice $(n=10)$. Each histogram plots the diameter of the pupil against the luminance of the stimulus light: $0.01,10$, and $1000 \mathrm{~cd} / \mathrm{m}^{2}$. The horizontal bars give the standard error of the mean. $C$, Postrotatory nystagmus $(P R N)$ : the mean frequency of postrotatory eye movements (number of eye movements per $5 \mathrm{sec}$ ) is plotted for normal $(n=36)$, pearl $(n=18)$, and retinal dystrophic mice $(n$ $=36$ ). The 5-sec measured period started immediately after the rotation stopped. Horizontal bars indicate the standard error of the mean.

bright stimuli $\left(1000 \mathrm{~cd} / \mathrm{m}^{2}\right)$ (Fig. $1 B$ ). In both normal and pearl mice, the pupillary diameter decreased to $50 \%$ of the dark-adapted values at luminances that were $2 \mathrm{log}$ units less than those required by mice with retinal degeneration (Fig. $1 B$ ).

To test if pearl mice were unable to generate eye movements at all, we placed the mice on a turntable, rotated them for $6 \mathrm{sec}$, and then observed their eyes for postrotatory nystagmus. Pearl mice, wild mice, and retinal dystrophic mice all generated postrotatory nystagmus (Fig. 1C).

From these behavioral experiments, we concluded that, although pearl mice lack visually evoked eye movements, they have a normal pupillary light reflex and they are able to respond to vestibular stimulation with normal eye movements.

\section{Morphology}

Retinas of pearl mice and normal mice were examined in $1-\mu \mathrm{m}$ plastic sections. No differences were found in the overall layering of the retina, the morphology of the cells, and the density of cells within the layers. In particular, there was no indication of the photoreceptor loss evident in retinas of mice with retinal degeneration. Coronal sections of brains from pearl mice and control mice revealed no differences in the cytoarchitecture in either the primary visual cortex or the superior colliculus.

Ocular injection of radioactive label in both normal and pearl mice resulted in heavy primary labeling of the contralateral superior colliculus and lateral geniculate nucleus (LGN) as well as faint transneuronal label in layer IV of the primary visual cortex. Ipsilateral to the injected eye in both types of mice, the primary projections to the lateral geniculate nucleus and superior colliculus were labeled. Relative to the contralateral projection, the ipsilateral projections were considerably sparser in pearl than in pigmented mice. The ipsilateral portion of the LGN in pearl was reduced in size and fragmented in outline as described for other mouse pigmentation mutants (LaVail et al., 1978). Figure 2 shows autoradiographs of comparable coronal sections through the central superior colliculus of a normal mouse (above) and a 


\section{$+/+$}

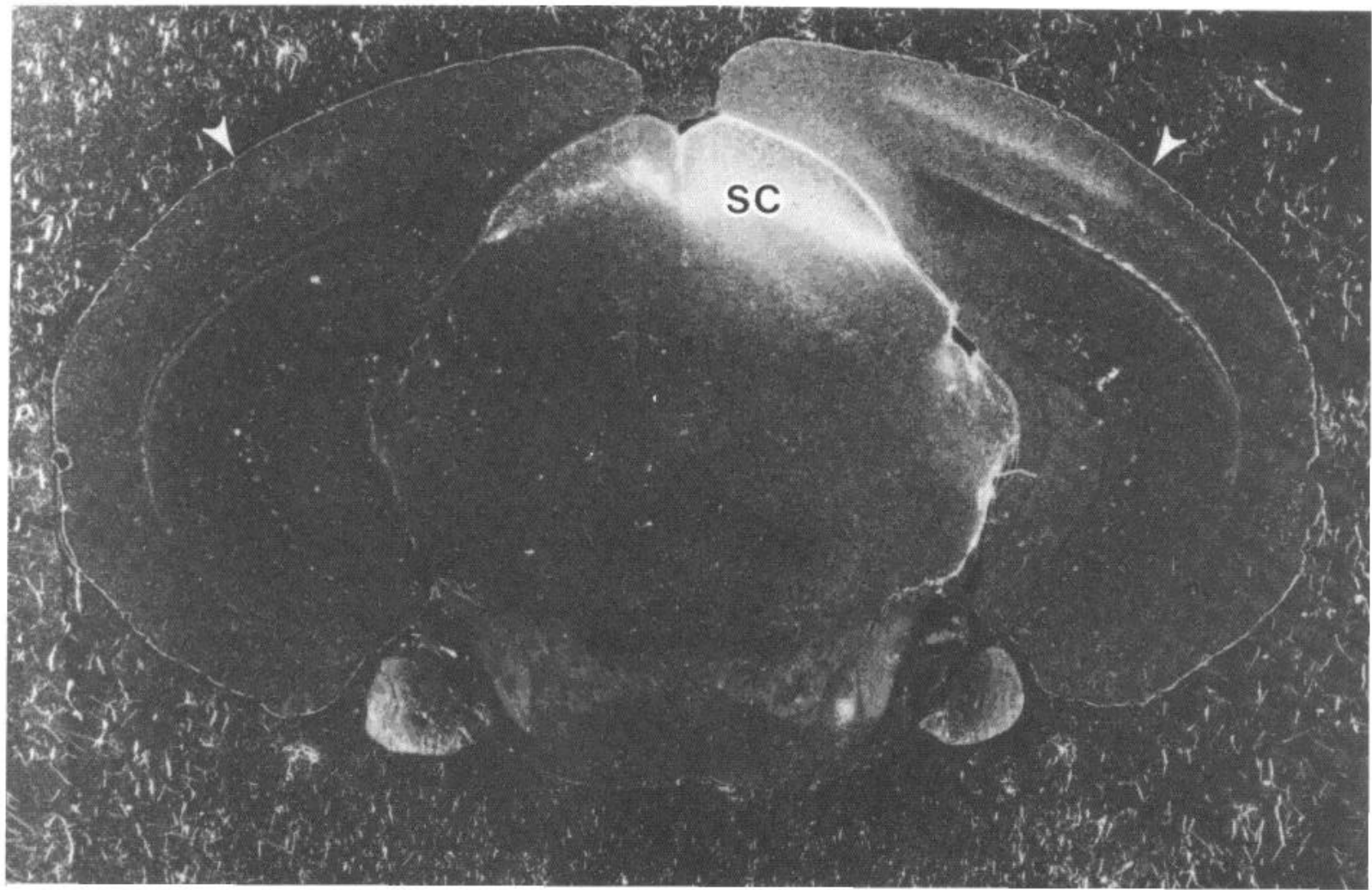

pe pe

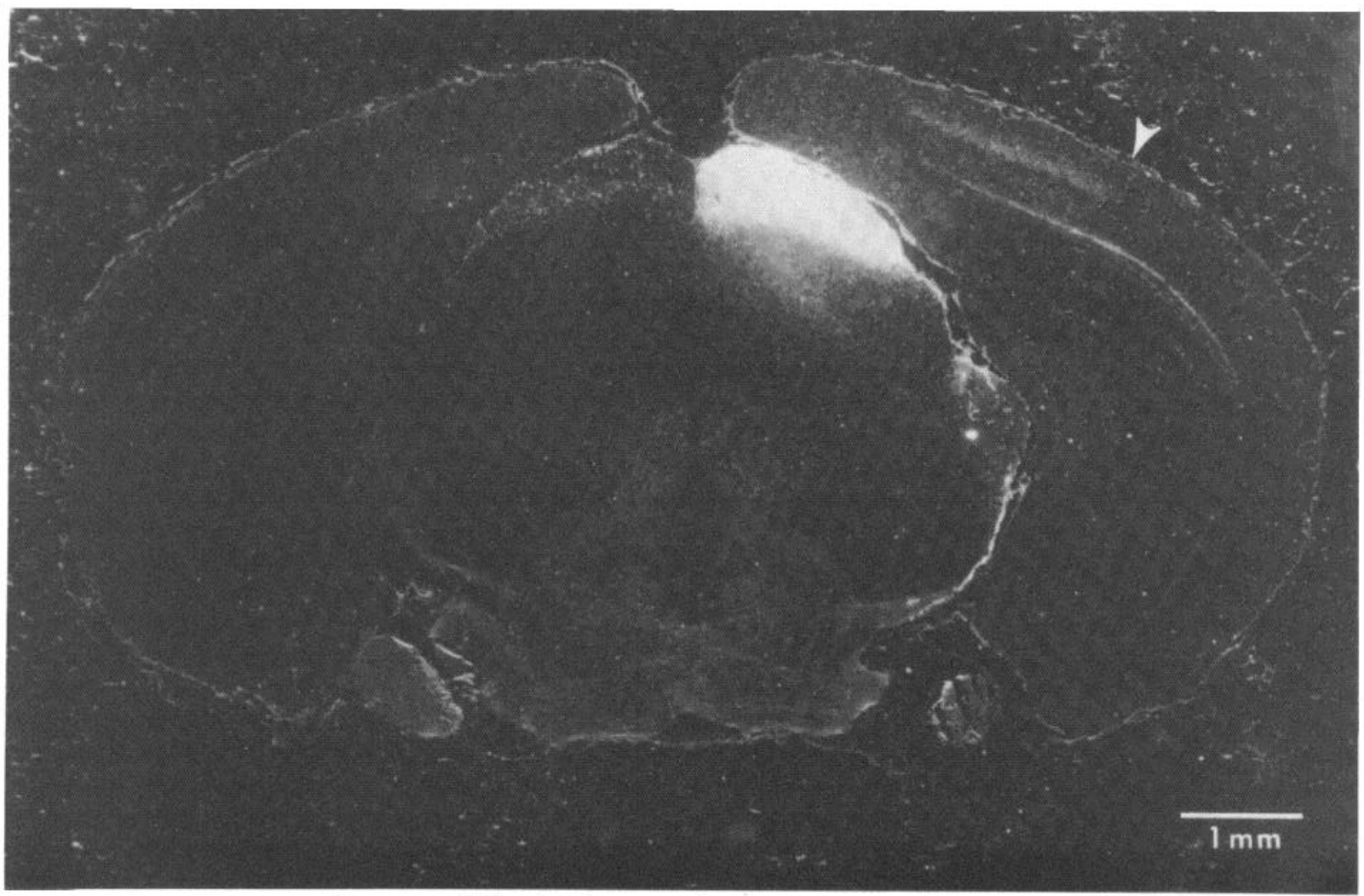

Figure 2. 'T'ransneuronal autoradiographs of the visual systems in normal and pearl mice. Dark-field autoradiographs of coronal sections through the superior colliculus and the visual cortex of a normal mouse (above) and a pearl mouse (below). The left eye had been injected with radioactive proline and fucose 10 days prior to perfusion. The contralateral superior colliculi ( $S C$, right in the figure) are labeled heavily in both types of mice. Note the sparser labeling in the ipsilateral tectum of pearl as compared to normal. Transneuronal labeling results in heavy labeling of the contralateral primary visual cortex in both normal and pearl mice; the ipsilateral primary visual cortex is labeled lightly in the normal mouse and can be seen only at higher magnification in the pearl mouse (arrowhead showing 17/18a border). The bar indicates $1 \mathrm{~mm}$. 
pearl mouse ( below). In the normal mouse, the ipsilateral projection to the tectum ended mainly in several dense clusters at the level of the stratum opticum, while in pearl, only a few specks of ipsilateral label were visible in the section shown. At more rostral levels in the superior colliculus, a sparse ipsilateral projection in pearl also could be seen to end as deeply as in the normal mouse. Transneuronal labeling via the ipsilateral LGN to the primary visual cortex was visible in the lateral portions of area 17 of the normal mouse cortex (Fig. 2). In pearl, the ipsilateral cortical projection was present but so weak that it was barely discernible in the section shown in Figure 2 or at any other level or in any other section.

\section{Electrophysiology}

Electroretinogram. We recorded the electroretinograms of six pearl mice and eight normal mice in response to brief flashes of light that ranged in luminance from $10^{-3}$ to $10^{4} \mathrm{~cd} / \mathrm{m}^{2}$. There was no consistent difference between the waveforms of pearl and those of normal mice (Fig. 3).

For each mouse, the amplitudes of the A and B waves were plotted against luminance (Fig. $4 A$ ). The maximal voltages in pearl were smaller than in the normal mouse on the average, but there was considerable overlap of the maximal voltages. The normalized amplitudes for each mouse were plotted against the logarithm of stimulus luminance and comparison of these curves revealed no detectable difference between pearl and normal mice in the luminance for half-maximal amplitudes of the A or B waves (Fig. $4 B$ ).

Superior colliculus. In a series of preliminary experiments, we recorded from single units in the superior colliculus of both normal and pearl mice. In the course of testing pearl, it became obvious that cells in pearl mice required considerably brighter test stimuli than cells in normal mice when dim backgrounds were used (Fig. 5). The sensitivity defect of the cells in pearl mice did not seem to vary with the eccentricity of the receptive field but appeared similar over the entire visual field tested.

Pearl's light sensitivity (defined as the reciprocal of the luminance required to evoke a criterion response) then was measured for each of many different backgrounds. The pearl mouse had a large sensitivity defect for dim backgrounds but nearly normal sensitivity for brighter backgrounds: the magnitude of the sensitivity defect decreased steadily with increasing background luminance (Fig. 6). With any backgrounds between $10^{-5}$ and $10^{-1} \mathrm{~cd} / \mathrm{m}^{2}$, pearl units were about $2 \log$ units less sensitive than normal units $(p<0.05)$. When the background luminance was increased to $1 \mathrm{~cd} / \mathrm{m}^{2}$, the difference in sensitivity between pearl and normal units dropped to about $1 \log$ unit, and when the background luminance was increased to $100 \mathrm{~cd} / \mathrm{m}^{2}$, there were no significant differences in sensitivity (Fig. 6). A summary of the statistical analysis is given in Table I.

The sensitivity defect in the pearl mouse was not due to receptive field areas being smaller than in normal mice: the averaged receptive field area from pearl mice was $151 \mathrm{deg}^{2}\left(\mathrm{SE}=65 \mathrm{deg}^{2}\right)$; in normal mice, this area was $111 \mathrm{deg}^{2}\left(\mathrm{SE}=30 \mathrm{deg}^{2}\right)$. When the incremental sensitivity curves were expressed in terms of quanta
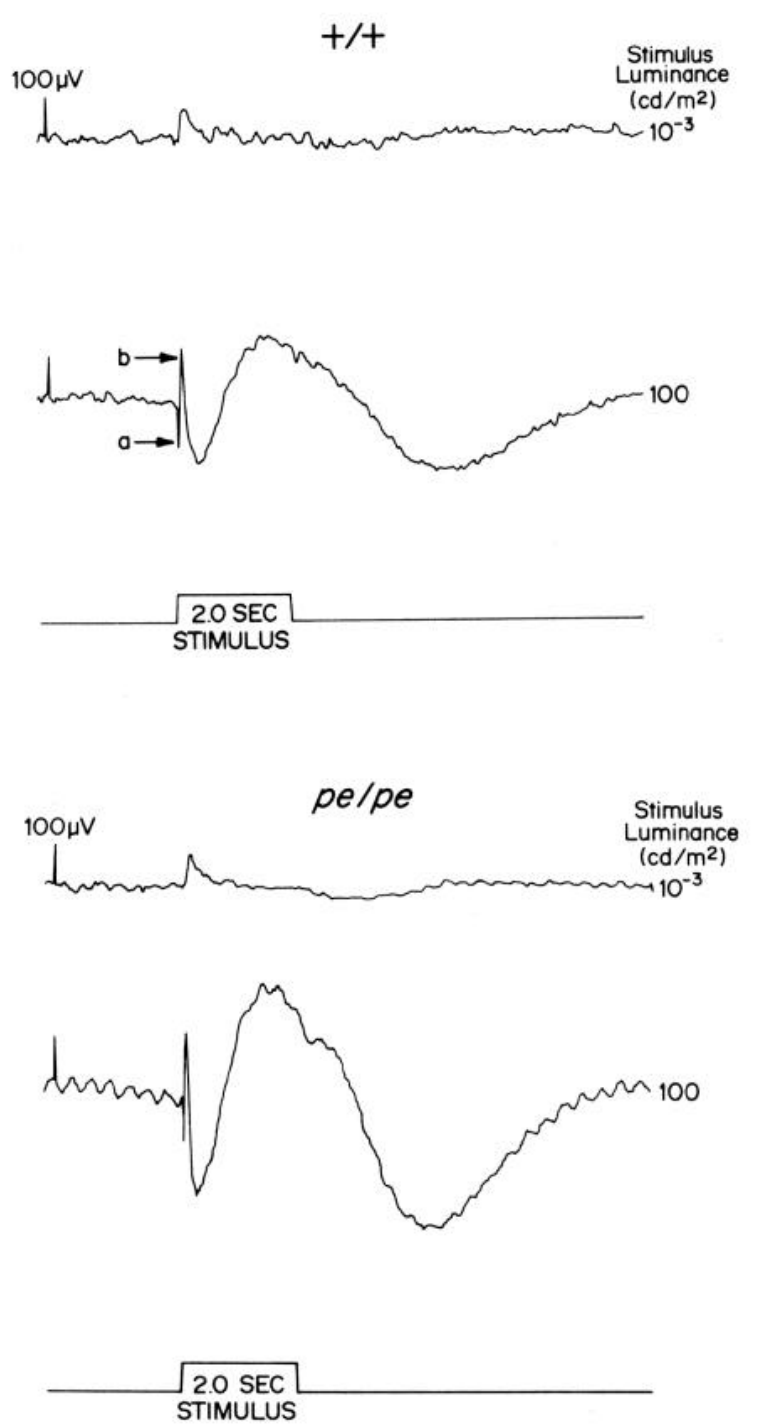

Figure 3. Electroretinographic responses (ERG). ERG waves from a normal mouse (top) and a pearl mouse (bottom). The luminance of the stimulus is given to the right of each trace. The $100-\mu \mathrm{V}$ calibration pulse appears at the beginning of each trace; a $2-\sec$ time interval is indicated by the stimulus trace. $a$, A wave; $b$, B wave.

incident upon the cell's receptive field instead of luminance, a 2-log-unit difference was still found between pearl and normal mice.

Another possible explanation for the apparent sensitivity defect in pearl might be a prolonged time course of dark adaptation. The time of recovery of sensitivity after the presentation of a bright adapting light for four pearl and four normal mice was tested (1 cell per mouse). After the adapting light was extinguished, the mean time for a $50 \%$ recovery of the decrease in light sensitivity was 16 min for pearl and $21 \mathrm{~min}$ for normal mice (Fig. 7).

\section{Discussion}

The pearl mutation appears to be a point mutation. Hence, there could be a finite chance for the mutant allele to revert to the normal allele. Since point mutations caused by copying errors may occur at regions of the 

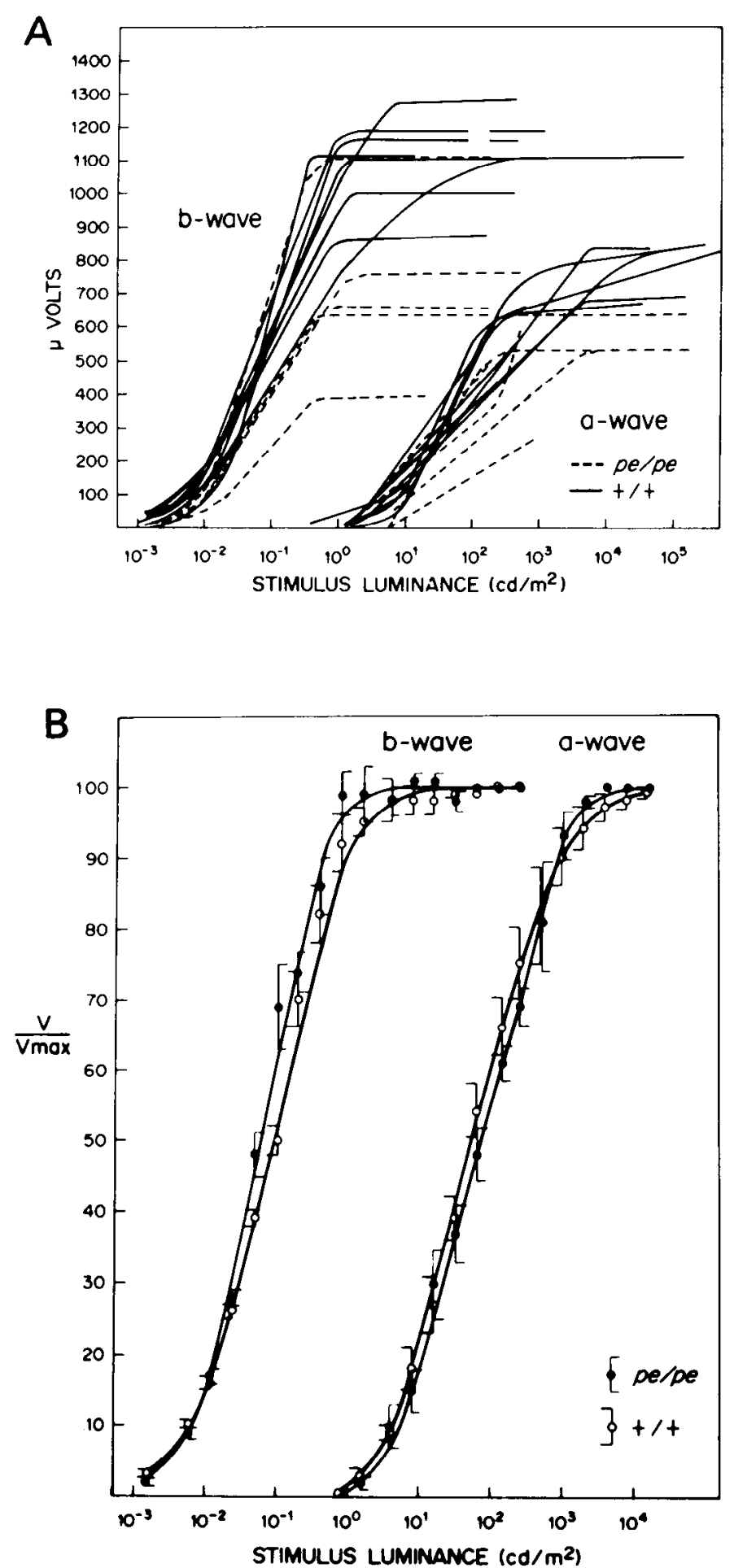

Figure 4. Intensity-response curves of the ERG from normal and pearl mice. $A$, Raw data: the amplitude of the $A$ wave was plotted against the luminance of the stimulus for both pearl and normal mice. The maximum responses obtainable from pearl mice tended to be less than those from normal mice although there was a large variation within each group and each animal. Each curve represents the averaged response to multiple stimuli. $B$, Averaged curves: the amplitude of the response was divided by the peak response amplitude to give the normalized response. The $B$ wave curve is on the left and the $A$ wave is on the right. Pearl is indicated by the solid circles and standard error bars pointing to the right; normal is indicated by open circles and standard error bars pointing to the left. Average curves were fitted to the points by eye. genome which have a high probability for this type of error, other spontaneous mutations are possible in this region. Indeed, a fairly high rate of somatic cell reversions has been observed in pearl (Russell and Major, 1956), and a second mutation at the pearl locus has been found (A. E. Searle, personal communication). The single genetic alteration in pearl causes at least four seemingly unrelated, pleiotropic effects: dilution of coat color, lack of visually evoked eye movements (OKN), reduced ipsilateral projection, and reduced dark-adapted light sensitivity.

Whether these pleiotropic expressions can each be traced by an independent pathway to the defective gene product or whether one or more of the different expressions are dependent on one another is of interest. For example, the reduced ipsilateral projection cannot be responsible for the reduced dark-adapted sensitivity, since this reduced sensitivity was observed in recordings from cells having only contralateral retinal input. Likewise, the reduced dark-adapted sensitivity cannot be the cause of the lack of OKN, since the pearl animals showed no sensitivity loss at the light levels used to test for OKN.

Overall, it appears that only one causal relationship might exist, namely that the reduced ipsilateral projection might in some way cause the lack of OKN in pearl. Most mutants with hypopigmentation of their coat have reduced ipsilateral projections (mouse: Dräger, 1974; LaVail et al., 1978; Dräger and Olsen, 1980; Balkema and Dräger, 1980; rat: Lund, 1965; mink: Sanderson et al., 1974; rabbit: Giolli and Guthrie, 1969; cat: Guillery, 1969; and human: Creel et al., 1974). Furthermore, many hypopigmentation mutants also lack or have abnormal OKN (mouse: G. W. Balkema, Jr., L. H. Pinto, and J. W. Vanable, Jr., manuscript in preparation; rat: Precht and Cazin, 1979; rabbit: Collewijn et al., 1978). Clearly hypopigmentation of the coat does not directly cause either a reduced ipsilateral projection or a lack of OKN, but they are highly correlated. Therefore, the lack of OKN in hypopigmentation mutants need not be due directly to the reduced ipsilateral projections in these animals. It is worth noting, however, that the visual nucleus most likely to be involved in generating horizontal $\mathrm{OKN}$ is the nucleus of the optic tract (Collewijn, 1975; Collewijn et al., 1978) and that, in normal mice, the retinal input to this nucleus is almost entirely contralateral (Scalia, 1972), although this nucleus may depend upon an ipsilateral input from other visual regions. In summary, although the possibility that the lack of OKN may be due to a reduced ipsilateral input cannot be excluded, we have found no evidence to support this hypothesis.

The anatomical site of the OKN defect in pearl is not clear. Obviously, any defective pathways in the optic nerve could project to nuclei responsible for OKN. Although experiments by Collewijn and his colleagues (1978) in the rabbit show that the nucleus of the optic tract is involved in OKN, similar studies in pearl mice have been unfeasible due to the small size of this mammal. Recordings from retinal ganglion cell axons within the optic nerve suggest that, at the light levels at which the OKN testing was performed, both the light sensitivity and the receptive field characteristics of cells in pearl are similar to those of normal mice (Balkema and Pinto, 1979). Furthermore, judging from the normal postrota- 


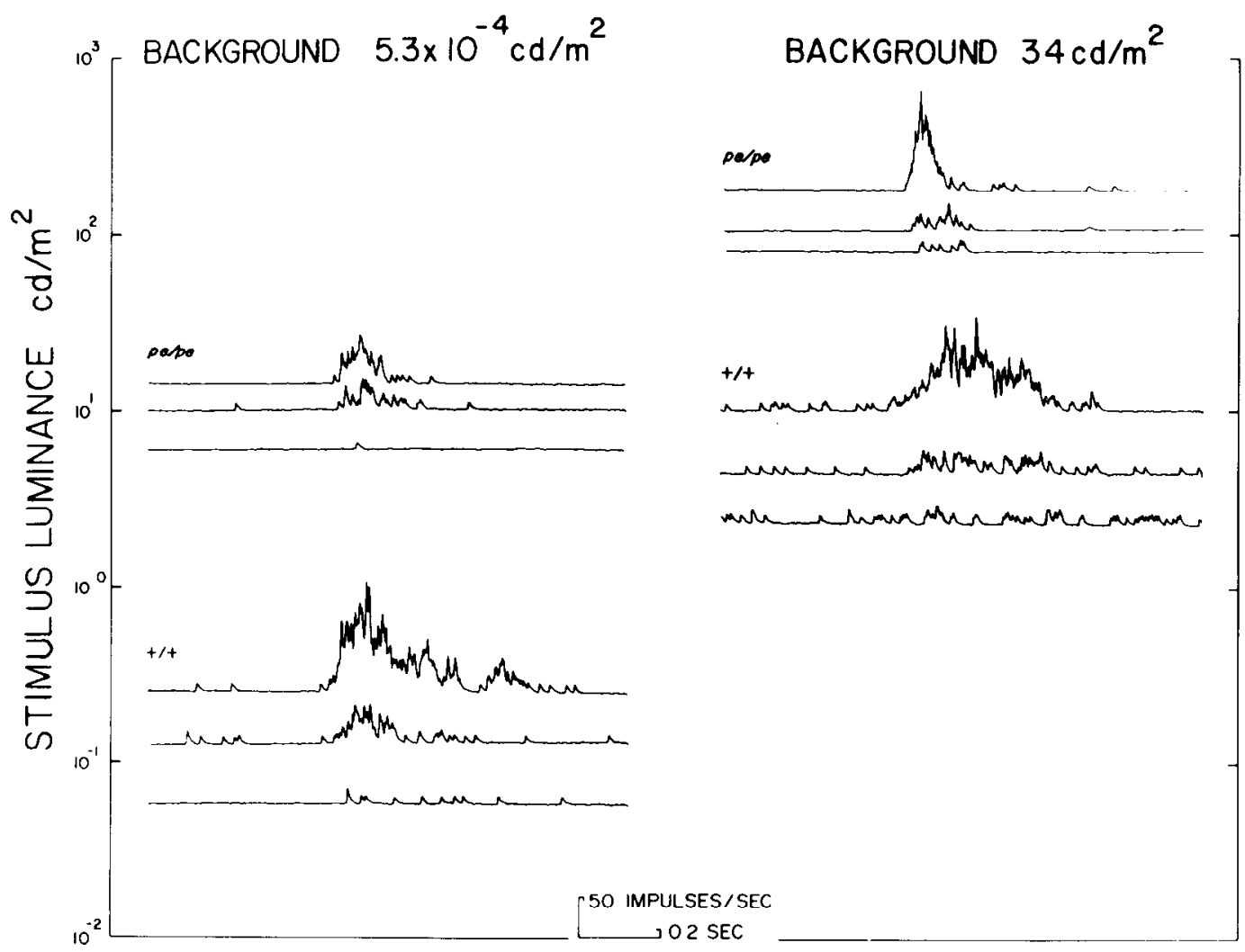

Figure 5. Pulse density plots from cells in the superior colliculus. Plots for three different stimulus luminances from a normal mouse and three different stimulus luminances from a pearl mouse at a $\operatorname{dim}$ background $\left(0.00053 \mathrm{~cd} / \mathrm{m}^{2}\right)$ are shown on the left. Pulse density plots for three different stimulus luminances from the same normal mouse and three different stimulus luminances from the same pearl mouse at a bright background $\left(34 \mathrm{~cd} / \mathrm{m}^{2}\right)$ are shown on the right. Although the spontaneous firing rate for the pearl cell was less than the normal cell in this example, overall there was not a consistent difference between pearl and normal cells with regard to the spontaneous firing rate.

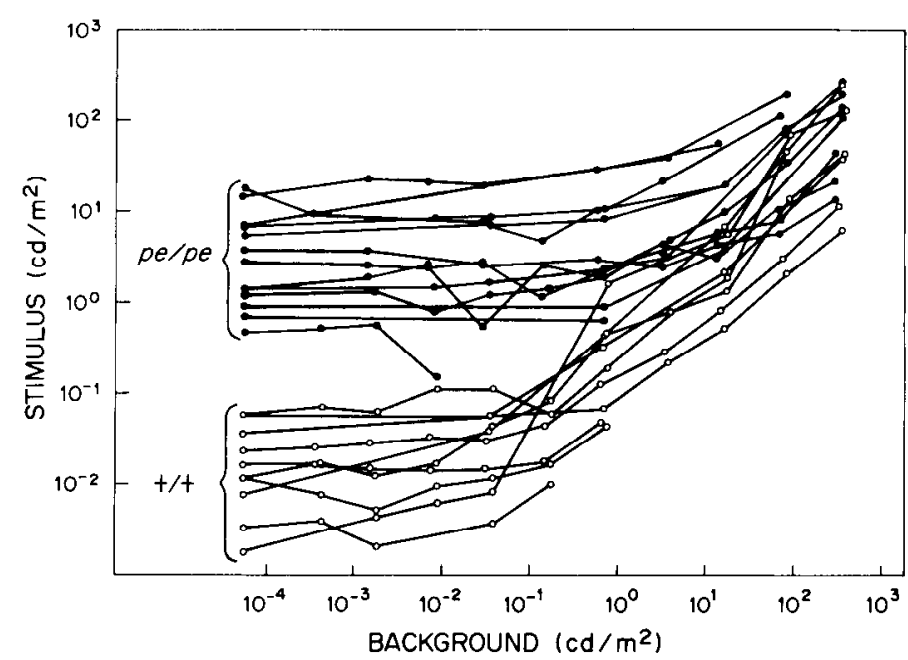

Figure 6. Incremental sensitivity curves from pearl and normal mice. The stimulus luminance required to evoke a criterion response for background luminances from $10^{-4}$ to $10^{2} \mathrm{~cd} / \mathrm{m}^{2}$ for 13 pearl cells $(O)$ and 10 normal cells $(O)$ in the superior colliculus is shown.

tory nystagmus, pearl's oculomotor nuclei and eye muscles are presumably normal. These findings suggest that the pearl mutation does not affect the final common pathway for eye movements.
TABLE I

Analysis of the variance from the mean sensitivities of normal and pearl mice

\begin{tabular}{cccrc}
\hline Barkground & $\begin{array}{c}\text { Log } \\
\text { Sensitivity } \\
\text { Difference }^{a}\end{array}$ & $\begin{array}{c}\text { Degrees of } \\
\text { Freedom }\end{array}$ & $F$ Value & $\begin{array}{c}\text { Probability }^{b} \\
p\end{array}$ \\
\hline $\log \left(c d / m^{2}\right)$ & & & & \\
-4.8 & 2.07 & 8 & 28.06 & 0.001 \\
-4.0 & 1.87 & 4 & 7.26 & 0.055 \\
-3.3 & 2.33 & 5 & 11.53 & 0.025 \\
-2.6 & 1.96 & 6 & 11.25 & 0.025 \\
-2.0 & 2.13 & 6 & 18.71 & 0.005 \\
-1.3 & 1.97 & 4 & 5.74 & 0.100 \\
-0.7 & 0.91 & 7 & 6.47 & 0.050 \\
0.0 & 0.60 & 7 & 1.23 & 0.500 \\
0.7 & 0.44 & 7 & 1.09 & 0.500 \\
1.4 & 0.32 & 7 & 0.40 & 0.750 \\
2.0 & 0.26 & 5 & 0.08 & 0.750 \\
\hline
\end{tabular}

${ }^{a}$ Log sensitivity difference refers to the difference in the average of the $\log$ of the sensitivities between 10 normal cells and 13 pearl cells.

${ }^{b}$ The individual incremental sensitivity curves were approximately normally distributed; thus a parametric analysis of variance (Ostle, 1963) was used with Satterthwaite's (1946) correction.

The results from intravitreal injections of labeled amino acids suggested that pearl has a decreased ipsilateral retinofugal projection. This confirms the results of others demonstrating a reduced ipsilateral retinofugal 


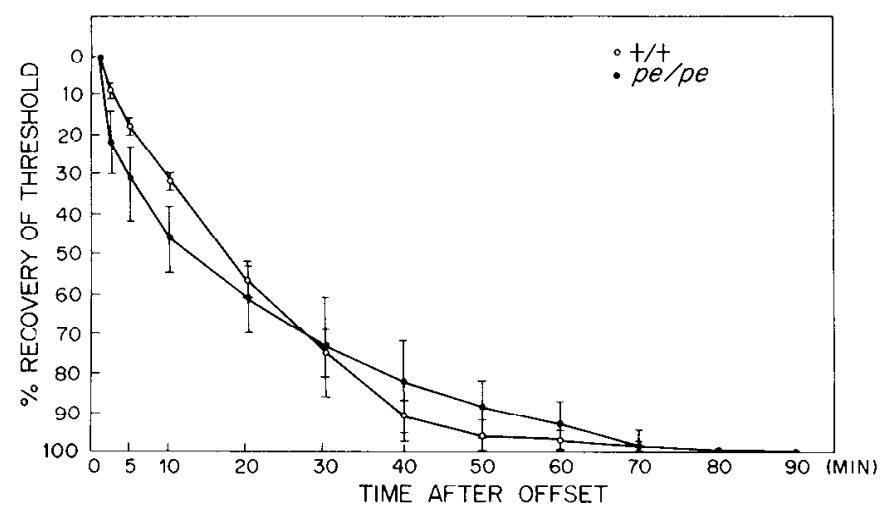

Figure 7. Time course of dark adaptation from single cells in the superior colliculus. The time course of recovery of thresholds after a 180-sec exposure to a background luminance of 600 $\mathrm{cd} / \mathrm{m}^{2}$ is shown. The responses from 4 normal cells were averaged to give the curve with open circles. The responses from 4 pearl cells were averaged to give the curve with solid circles (see "Materials and Methods" for details).

projection in hypopigmentation mutants. Recently, the reduction in pearl's ipsilateral projection has been quantified by counting the ipsilaterally projecting ganglion cells in retinal whole mounts (Balkcma and Dräger, 1980).

Although the cause of pearl's reduced dark-adapted sensitivity is unknown, agreement of our measurements of absolute dark-adapted sensitivity in wild type mice with those of others (Hellner, 1966; Dräger and Hubel, 1978; for discussion, see Balkema, 1979; Mangini and Pinto, 1980) implies that our determination of pearl's absolute sensitivity is correct and that, indeed, pearl mice do show a marked decrease in their dark-adapted sensitivity. However, there is little evidence that pearl's reduced dark-adapted sensitivity, as measured in the superior colliculus, is due to a photoreceptor defect, since the A wave of the ERG in pearl under scotopic conditions was similar in waveform and semi-saturation luminance to that of normal mice. The B wave of the electroretinogram is a more sensitive measure of retinal activity evoked by stimuli of low luminance. The $B$ wave responded to stimuli with luminances as low as $10^{-3} \mathrm{~cd} / \mathrm{m}^{2}$ in both normal and pearl mice. At these luminances, pearl has a tectal sensitivity defect of over 2 log units; yet the $\mathrm{B}$ wave appeared normal.

Recently, measurements of retinal ganglion cell sensitivity in intact, anesthetized pearl mice have localized the light sensitivity deficit to the pearl retina (Balkema and Pinto, 1979). The agreement of our pearl A wave recordings with those of normal mice suggest that the pearl photoreceptors are not affected significantly. Our results also suggest that the locus of pearl's sensitivity defect is one that does not affect the structures that generate the B wave significantly. Thus, the pearl mutation appears primarily to affect structures between the photoreceptors and the retinal ganglion cells but in a way that attenuates the electroretinogram insignificantly.

\section{Conclusions}

The effects of the pearl mutation include several subtle and specific alterations of the visual system. These alterations contrast with the gross abnormalities produced by mutations such as retinal degeneration and ocular retardation. Behaviorally, the pearl mutant has been found to lack the optokinetic nystagmus reflex. Anatomically, the pearl mutant has a reduced ipsilateral projection to the superior colliculus, lateral geniculate, and visual cortex. Physiologically, the pearl mutant has a 2-log-unit sensitivity defect with dim backgrounds.

Because of the specific nature of these defects of pearl mutants, this mutation may form a model for several forms of human night blindness and may be useful for examining the common aspects of processes such as the development of pigmentation in the mouse and its visual pathways. Finally, because mutations at the pearl locus can produce visual defects that are amenable to study, further study may allow the functions that are encoded for by the locus to be understood.

\section{References}

Balkema, G. W., Jr. (1979) A study of visual abnormalities in mulant mice: A retinal sensitivity defect in the mutant mouse pearl. Doctoral thesis, Purdue University, West Lafayette, IN.

Balkema, G. W., Jr., and U. C. Dräger (1980) Retinal ganglion cell projections in pigmentation mutants of the mouse. Invest. Ophthalmol. Vis. Sci. ARVO Suppl. 19: 2.

Balkema, G. W., Jr., and L. H. Pinto (1979) Retinal sensitivity defect in the mutant mouse pearl. Soc. Neurosci. Abstr. 5: 776.

Carter-Dawson, L. D., and M. M. LaVail (1979) Rods and cones in the mouse retina. I. Structural analysis using light and electron microscopy. J. Comp. Neurol. 188: 245-262.

Collewijn, H. (1975) Oculomotor areas in the rabbit's midbrain and pretectum. J. Neurobiol. 6: 3-22.

Collewijn, H., B. J. Winterson, and M. F. W. Dubois (1978) Optokinetic eye movements in albino rabbits: Inversion in anterior visual field. Science 199: 1351-1353.

Creel, D., C. J. Witkop, Jr., and R. A. King (1974) Asymmetric visually evoked potentials in human albinos: Evidence for visual system anomalies. Invest. Ophthalmol. Vis. Sci. 13: 430-440.

Dartnall, H. J. A.(1972) Photosensitivity. In Handbook of Sensory Physiology: Photochemistry of Vision, H. J. A. Dartnall, ed., Vol. III, Part 1, p. 143, Springer-Verlag, Berlin.

Dawe, A. R. (1953) Heart rate in mice. Doctoral thesis, University of Wisconsin, Madison, WI.

Dowling, J. E., and R. L. Sidman (1962) Inherited retinal dystrophy in the rat. J. Cell Biol. 14: 73-109.

Dräger, U. C. (1974) Autoradiography of tritiated proline and fucose transported transneuronally from the eye to the visual cortex in pigmented and albino mice. Brain Res. 82: 281-292.

Dräger, U. C. (1975) Receptive fields of single cells and topography in mouse visual cortex. J. Comp. Neurol, 160: 269-290.

Dräger, U. C., and D. H. Hubel (1978) Studies of visual function and its decay in mice with hereditary retinal degeneration. J. Comp. Neurol. 180: 85-114.

Dräger, U. C., and J. F. Olsen (1980) Origins of crossed and uncrossed retinal projections in pigmented and albino mice. J. Comp. Neurol. 191: 383-412.

Giolli, R. A., and M. D. Guthrie (1969) The primary optic projections in the rabbit. An experimental degeneration study. J. Comp. Neurol. 136: 99-125.

Green, E. L., ed. (1966) The Biology of the Laboratory Mouse, Ed. 2, p. 706, McGraw-Hill Book Co., New York.

Guillery, R. W. (1969) An abnormal retinogeniculate projection in Siamese cats. Brain Res. 14: 739-741.

Hardy, A. C., and F. H. Perrin (1932) The Principles of Optics, McGraw-Hill Book Co., New York. 
Hellner, K. A. (1966) Das adaptive Verhalten der Mausenetzhaut. Albrecht Von Graefes Arch. Klin. Exp. Ophthalmol. 169: $166-175$.

Hubel, D. H., and T. W. Wiesel (1971) Aberrant visual projections in the cat. J. Physiol. (Lond.) 218: 33-62.

LaVail, J. H., R. A. Nixon, and R. L. Sidman (1978) Genetic control of retinal ganglion cell projections. J. Comp. Neurol. 182: 399-421.

LaVail, M. M., and B. Battelle (1975) Influence of eye pigmentation and light deprivation on inherited retinal dystrophy in the rat. Exp. Eye Res. 21: 167-192.

Levick, W. R. (1972) Another tungsten-microelectrode. Med. Electron. Biol. Eng. 10: 510-515.

Liebman, P. A., and B. Entine (1968) Visual pigments of frog and tadpole Rana pipiens. Vision Res. 8: 761-775.

Lund, R. D. (1965) Uncrossed visual pathways of hooded and albino rats. Science 149: 1506-1507.

Mangini, N. J., and L. H. Pinto (1980) Ganglion cell responses in isolated retinas of normal and pearl mice. Invest. Ophthalmol. Vis. Sci. ARVO Suppl. 19: 6 .

Mitchiner, J. C., L. H. Pinto, and J. W. Vanable, Jr. (1976) Visually evoked eye movements in the mouse (Mus musculus). Vision Res. 16: 1169-1171.

Montemurro, D. G., and K. H. Dukelow (1972) A Stereotaxic Atlas of the Diencephalon and Related Structures of the Mouse, Futura Publishing Co., Mount Kisco, New York.

Nagy, Z. M., and J. R. Misanin (1970) Visual perception in the retinal degenerate $\mathrm{C} 3 \mathrm{H}$ mouse. J. Comp. Physiol. Psychol. 72: $306-310$.

Ostle, B. (1963) Statistics in Research, Iowa State University Press, Ames, IA.

Precht, W., and L. Cazin (1979) Functional deficits in the optokinetic system of albino rats. Exp. Brain Res. 37: 183186.

Rodieck, R. W. (1973) The Vertebrate Retina. Principles of Structure and Function, W. H. Freeman, San Francisco.

Russell, L. B., and M. H. Major (1956) A high rate of somatic reversion in the mouse. Genetics 4: 658 .

Sanderson, K. J., R. W. Guillery, and R. M. Shackelford (1974) Congenitally abnormal visual pathways in mink (Mustula vision) with reduced retinal pigment. J. Comp. Neurol. 154: 225-248.

Sarvella, P. (1954) Pearl, a new spontaneous coat and eye color mutation in the house mouse. J. Hered. 45: 19-20.

Satterthwaite, F. E. (1946) An approximate distribution of estimates of variance components. Biometrics 2: 110 .

Sawin, P. V., and D. Glick (1943) Atropinesterase, genetically determined enzymes in rabbit. Proc. Natl. Acad. Sci. U. S. A. 29: 55-59.

Scalia, F. (1972) The termination of retinal axons in the pretectal regions of mammals. J. Comp. Neurol. 145: 223-258.

Wyszecki, G., and W. S. Stiles (1967) Color Science. Concepts and Methods, Quantitative Data and Formulas, John Wiley \& Sons, Inc., New York. 